\title{
Patient-reported fatigue in patients with rheumatoid arthritis who commence biologic therapy: A longitudinal study
}

\author{
Hege Selheim Rinke ${ }^{\text {Corresp.. }}{ }^{1,2}$, Clara Beate Gram Gjesdal ${ }^{1,3}$, Heidi Markussen ${ }^{2,4}$, Jörg Assmus ${ }^{5}$, Gerd Karin \\ Natvig ${ }^{2}$ \\ 1 Department of Rheumatology, Haukeland University Hospital, Bergen, Norway \\ 2 Department of Global Public Health and Primary Care, University of Bergen, Bergen, Norway \\ 3 Department of Clinical Science, University of Bergen, Bergen, Norway \\ 4 Department of Thoracic Medicine, Haukeland University Hospital, Bergen, Norway \\ ${ }^{5}$ Centre for Clinical Research, Haukeland University Hospital, Bergen, Norway \\ Corresponding Author: Hege Selheim Rinke \\ Email address: hegerinke@gmail.com
}

\begin{abstract}
Aims and objectives. To examine changes in patient-reported fatigue, over a twelve month period, in rheumatoid arthritis patients who commence biologic treatment, and to identify possible predictors for such changes.
\end{abstract}

Background. Fatigue is a burdensome symptom for patients with rheumatoid arthritis. Despite biologics being effective in reducing disease activity, patients still report fatigue.

Design. A longitudinal observational study.

Methods. A total of 48 patients were enrolled in the study. Fatigue was measured by the Fatigue Severity Scale. Independent samples T-tests were used to test gender differences, and paired samples Ttests were used to measure differences between repeated measures. Bivariate and multiple regression analyses were used to examine potential predictors for changes in fatigue, such as age, sex, Disease Activity Score 28, pain and physical and emotional well-being.

Results. Forty-seven patients completed the study. From baseline to 12-month follow-up, fatigue decreased significantly in both women and men. Analyses of predictors were performed step-wise, and the final model included sex and physical well-being. The results from this final step showed that female sex was the only significant predictor for changes in fatigue.

Conclusion. Patients commencing biologic therapy reported a significant reduction in fatigue. Female sex was a significant predictor of changes in fatigue.

Relevance to clinical practice. Despite improvements in pharmacological treatment, patients with rheumatoid arthritis still report fatigue. This is a multifaceted health problem encompassing personal and emotional factors in addition to the clinical factors directly connected to the disease. 


\section{Title of the research paper}

2 Patient-reported fatigue in patients with rheumatoid arthritis who commence biologic therapy: A

3 longitudinal study

4 Authors: Hege Selheim Rinke 1, 2, Clara Beate Gram Gjesdal 1, 3, Heidi Markussen 2, 4, Jörg

5 Assmus 5 \& Gerd Karin Natvig 2

61 Department of Rheumatology, Haukeland University Hospital, Bergen, Norway

72 Department of Global Public Health and Primary Care, University of Bergen, Bergen,

8 Norway

9 Department of Clinical Science, University of Bergen, Bergen, Norway

104 Department of Thoracic Medicine, Haukeland University Hospital, Bergen, Norway

115 Centre for Clinical Research, Haukeland University Hospital, Bergen, Norway

12 Correspondence:

13 Selheim Rinke

14 hegerinke@gmail.com 


\section{Patient-reported fatigue in patients with rheumatoid arthritis

Aims and objectives. To examine changes in patient-reported fatigue, over a twelve month

period, in rheumatoid arthritis patients who commence biologic treatment, and to identify possible predictors for such changes.

Background. Fatigue is a burdensome symptom for patients with rheumatoid arthritis. Despite biologics being effective in reducing disease activity, patients still report fatigue.

Design. A longitudinal observational study.

Methods. A total of 48 patients were enrolled in the study. Fatigue was measured by the Fatigue

Severity Scale. Independent samples T-tests were used to test gender differences, and paired samples T-tests were used to measure differences between repeated measures. Bivariate and multiple regression analyses were used to examine potential predictors for changes in fatigue, such as age, sex, Disease Activity Score 28, pain and physical and emotional well-being.

Results. Forty-seven patients completed the study. From baseline to 12-month follow-up, fatigue decreased significantly in both women and men. Analyses of predictors were performed stepwise, and the final model included sex and physical well-being. The results from this final step showed that female sex was the only significant predictor for changes in fatigue.

44 Female sex was a significant predictor of changes in fatigue.

Relevance to clinical practice. 
47 Despite improvements in pharmacological treatment, patients with rheumatoid arthritis still

48 report fatigue. This is a multifaceted health problem encompassing personal and emotional

49 factors, in addition to the clinical factors directly connected to the disease.

50 What does this paper contribute to the wider global clinical community?

51 *Fatigue is one of the most burdensome symptoms from the patient perspective.

$52 *$ The reduction in fatigue observed after twelve months was higher in women than in men.

53 *Female sex was the most important predictor of changes in fatigue. 


\section{Introduction}

75 Rheumatoid arthritis (RA) is an inflammatory joint disease which may cause joint damage, disability and fatigue (Scott, Wolfe, \& Huizinga, 2010). RA patients experience fatigue as unpredictable, overwhelming and different from normal tiredness (Feldthusen et al., 2013).

Fatigue is caused by numerous factors. This might due to immunological disorders, hormonal imbalances, decrease in oxygenation, and exogenous processes induced by drugs (Dupond, 2010). A conceptual model for fatigue suggests inter-relationships between and within the RA disease process, personal issues, feelings, thoughts and behaviors (Hewlett et al., 2011a). Fatigue in RA is under-recognized and undertreated (Hewlett et al., 2005). Furthermore, it is one of the most burdensome symptoms from the patient perspective (Kirwan et al., 2007; van Tuyl et al.,

84 2007). Over the last decades biologic agents have caused a paradigm shift in the treatment of RA, and biologics are effective in reducing disease activity, inflammation, pain and joint damage in RA (Scott et al., 2010). This reduction of disease-related components may affect the level of RA fatigue, and previous research has shown that both anti-tumor necrosis factor (anti-TNF) and non-anti-TNF biologics produce similar improvements in fatigue (Almeida et al., 2016). However, patient-reported consequences of disease activity may differ from the assessments made by health professionals (Studenic et al., 2012).

\section{Background}


93 Recommendations endorsed by the European League Against Rheumatism and the American

94 College of Rheumatology encourage all clinical trials to report fatigue (Aletaha et al., 2008;

95 Kirwan et al., 2007). Fatigue is a patient-reported measure and can incorporate one single item or 96 multiple items. Furthermore, the scales can have a unidimensional or multidimensional structure.

97 The Fatigue Severity Scale (FSS) is a disease-specific questionnaire intended to assess fatigue in

98 multiple sclerosis and systemic lupus patients, but it is also used in RA studies (Diniz et al.,

99 2017; Gok Metin \& Ozdemir, 2016; Hussain et al., 2015). The FSS is better at detecting changes

100 than generic questionnaires (Hewlett, Dures, \& Almeida, 2011b). As fatigue in RA patients is

101 measured by various patient-reported outcome measures (Hewlett, Dures, \& Almeida, 2011b;

102 Pouchot et al., 2008), and as results from these measures are difficult to compare, the review

103 below will mainly refer to research based on the FSS.

104

\section{Effect of biologic therapy on fatigue}

106 Only a few previous studies have examined the effect of biologic therapy on fatigue measured with a

107 disease-specific scale. In a double-blinded study, patients with Primary Sjögren's syndrome received

108 biologic therapy or placebo, and fatigue was measured using both the FSS and Visual Analogue Scale

109 (VAS). After four weeks of treatment there was no significant reduction in fatigue in these patients

110 (Norheim et al., 2012). On the other hand, another study has evaluated the effect of biologic therapy on

111 work ability, fatigue and functional disability in RA patients after six months. In this study, fatigue was

112 measured using the FSS and VAS, and the results demonstrated that biologics had a beneficial effect on

113 fatigue in patients with RA (Hussain et al., 2015).

\section{Predictors for changes in fatigue}


116 As stated by Ahmed and colleagues, patient-reported outcomes are important as they represent

117 information from the patient perspective that has not been interpreted by health personnel

118 (Ahmed et al., 2012) and such measures might provide additional and different information that

119 is relevant for both RA patients and physicians (Gossec, Dougados, \& Dixon, 2015).

120 Previous research has identified both patient-reported factors and more objective measures

121 evaluated by health personnel as predictors for fatigue. In a review containing both cross-

122 sectional and longitudinal studies, as well as several measures of fatigue, the results showed a

123 correlation between fatigue and patient-reported pain, physical function and depression

124 (Nikolaus et al., 2013). In a systematic review of cross-sectional, observational and cohort

125 studies examining psychological factors as predictors for fatigue, there was a consistent

126 correlation between patient-reported mood and fatigue, with low mood being associated with

127 increased fatigue (Matcham et al., 2015). The most common health personnel-reported measure

128 of disease activity in patients with RA is the Disease Activity Scale 28 (DAS28) (van Riel,

129 2014). To our knowledge, no previous studies including both patient-reported and health

130 personnel-reported measures have measured fatigue using the FSS. In a previous study of both

131 patient-reported and health personnel-reported outcomes, results showed that disease activity,

132 pain, sleep disturbance, and mental health were related to fatigue (Thyberg, Dahlstrom, \&

133 Thyberg, 2009). A review of correlations between different disease activity measures, pain and

134 fatigue showed that pain was the strongest factor associated with fatigue (Madsen et al., 2016).

135 In these studies gender has not been considered as a possible predictor for change in fatigue. In a

136 study of patients in remission or with low disease activity, pain was a significant predictor of

137 fatigue (Olsen et al., 2016). 
138 Regarding sociodemographic data, gender differences have been observed in previous research.

139 Female patients reported significantly higher fatigue measured by the FSS compared with

140 healthy controls (Buyuktas et al., 2015), and female participants reported more persistent fatigue

141 after four years than men did (Druce et al., 2015a). In a study, Thyberg et al. (2009) found that

142 women reported more fatigue measured by the VAS than men. Furthermore, one study found a

143 difference between the patient and physician assessment of global disease activity, and this

144 difference was more pronounced in women than in men (Lindstrom Egholm et al., 2015).

148 The aims of the present study were:

149 - To examine changes in patient-reported fatigue in RA patients who commence biologic

$150 \quad$ treatment.

151 - To identify possible predictors (sociodemographic as well as patient-reported and health 152 personnel-reported variables) for changes in fatigue.

153

\section{Methods}

\section{Design}

156 The study was carried out at a rheumatology specialist department in Western Norway. It was a

157 longitudinal study comparing fatigue levels over 12 months. Patients were assessed at baseline

158 (T0) and after 3 (T1), 6 (T2) and 12 months (T3). The study was part of an observational study

159 to explore ultrasonographic differences in total synovitis between seropositive and seronegative 
160 rheumatoid arthritis patients. The patients consented to participate in both studies at the same

161 time.

162 Inclusion criteria were as follows and the same as in the main study: 1) male or non-pregnant,

163 non-nursing female; 2) age between 18 and 75 years; 3) patient classified as having RA

164 according to the 2010 American College of Rheumatology/ European League Against

165 Rheumatism criteria (Aletaha et al., 2010); 4) treating rheumatologist and patient have decided

166 that biologic treatment is needed; 5) patient has had no prior biologic treatment; and 6) patient is

167 able and willing to give written informed consent and comply with the requirements of the study

168 protocol. Exclusion criteria: 1) abnormal renal function (serum creatinine $>142 \mu \mathrm{mol} / \mathrm{L}$ in

169 female and $>168 \mu \mathrm{mol} / \mathrm{L}$ in male, or GFR $<40 \mathrm{~mL} / \mathrm{min} / 1.73 \mathrm{~m}^{2}$; 2) abnormal liver function

170 (ASAT/ALAT $>3$ times normal), active or recent hepatitis, cirrhosis; 3) major co-morbidities

171 like severe malignancies, severe diabetic mellitus, severe infections, uncontrollable hypertension,

172 severe cardiovascular disease (New York Heart Association Functional Class 3-4) and/or severe

173 respiratory disease; 4) leukopenia and/or thrombocytopenia; 5) inadequate birth control,

174 pregnancy, and/or breastfeeding; 6) indications of active tuberculosis; and 7) psychiatric or

175 mental disorders, alcohol abuse or other abuse of substances, language barriers or other factors

176 which make adherence to the study protocol impossible.

177

178 Data collection

179 During the period from October 2011 to December 2014, all eligible patients were invited to

180 enter the study. A physical examination, including checking for co-morbidities and joint

181 counting, was performed by a rheumatologist. A study nurse coordinated the physical

182 examinations and blood testing, and managed the patient-reported questionnaires. When the last 
183 enrolled patient had been followed for 12 months the study was closed. The number of

184 participants is low, because the study was a subproject under the multicenter study

185 "Ultrasonographic differences in total synovitis between seropositive and seronegative

186 rheumatoid arthritis patients", and the Fatigue Severity Scale was not included in all subprojects.

\section{Treatment}

189 The patients in this study commenced their first biologic therapy (certolizumab, etanercept,

190 golimumab, infliximab or rituximab) according to standard procedures and doses.

19138 patients were on stable doses of methotrexate 3 months before baseline and until visit T1. 6

192 patients were taking leflunomide or hydroxychloroquine, and 4 patients had no synthetic disease-

193 modifying antirheumatic drugs (DMARDs).

194 A total of 28 patients were on a stable low dose of corticosteroids the last month before inclusion

195 and until visit T1. Patients were told to avoid analgesics for 24 hours prior to the visits if

196 possible.

\section{Assessments}

198 Fatigue was measured using the FSS, which is a 9-item questionnaire rated on a scale from 1 to

199 7, where 1 indicates strongly disagree and 7 indicates strongly agree. The FSS contains

200 statements on the severity of fatigue, and also the effect on a person's activities and lifestyle. The

201 developers of the FSS have suggested a cut-off of 4 for severe fatigue (Krupp et al., 1989). The

202 FSS is used in a number of diseases and is a reliable instrument for measuring fatigue (Valko et

203 al., 2008). The FSS has demonstrated good psychometric properties and is one of the few

204 measures that are able to detect change over time (Whitehead, 2009). There are different

205 Norwegian versions of the Fatigue Severity Scale questionnaire. In this study we used a 
206 questionnaire translated in 1995. As far as we know, this version of the questionnaire has not

207 been tested for psychometric properties. Nevertheless, it has been used in research and clinical

208 practice for several years (Johansen et al., 2018; Asprusten et al., 2018; De Rodez Benavent et

209 al., 2017).

210 Rheumatoid Arthritis Impact of Disease (RAID) was used to measure pain and physical and

211 emotional wellbeing (Gossec et al., 2009). The scale goes from 0-10. Pain is assessed from none

212 to extreme and physical and emotional wellbeing are assessed from very good to very bad. RAID

213 has been validated (Heiberg et al., 2011).

214 Disease activity can be measured by the Disease Activity Score 28 (DAS28). The purpose is to

215 combine single measures such as swollen and tender joints, erythrocyte sedimentation rate (ESR)

216 or C-reactive protein (CRP), and to include or exclude a general health assessment (Fransen,

217 Stucki, \& van Riel, 2003). In this study we wanted to use an objective tool for measuring disease

218 activity. Therefore, we chose DAS28 based on three variables: tender and swollen joint counts

219 and ESR (Fransen, Creemers, \& Van Riel, 2004). DAS28 has been validated to monitor disease

220 activity in RA (van Riel, 2014).

221

222 Statistical analyses

223 Descriptive statistics were used to describe sociodemographic, patient-reported and health

224 personnel-reported variables. The independent samples $t$-test was used to test for differences

225 between women and men. The paired samples $t$-test was used to test for differences between

226 measures at different points in time.

227 Linear mixed effect analyses were used to identify possible predictors of change in fatigue. In the

228 analyses, we added clinical variables such as DAS28, sociodemographic variables such as sex 
229 and age, and patient-reported variables such as pain and physical and emotional wellbeing. First,

230 a 0 -model containing time only was made using simple contrasts in time domain, i.e. a

231 comparison of each time point with baseline. In step 1, to estimate the main effect and interaction

232 effect, each predictor was put into a model containing time. The Akaikes information criterion

233 (AIC) was used as a criterion to decide whether the model fitted the data and also to compare the

234 models to the 0 -model by measuring the p-value and performing a likelihood ratio test. In step 2 ,

235 significant predictors were put into a model one by one. RAID subscales were added in order of

236 their AIC score. In step 3 only predictors contributing to the model were added.

237 We used a linear mixed effects model with simple contrasts including all time points, i.e. the

238 model has a built-in-adjustment for baseline. The main effect of a predictor is the effect at

239 baseline, while the interaction describes if and how the baseline effect changes over time.

240 The significance level was set to 0.05 . SPSS 23 for Windows (IBM Corp., Armonk, NY) and R

241 3.3.0 (R Core team, 2016) with the package nlme 3.1(Pinheiro et al., 2016) were used for the

242 statistical analyses.

244 Ethical considerations

245 The study was approved by the Regional Ethics committee for Medical Research (REK, 246 2011/490). All the patients received both oral and written information, and signed informed 247 consent.

\section{Results}


250 A total of 48 patients met the inclusion criteria, and gave consent to participate in the study. One

251 patient was excluded after 3 months because of acute illness and need of surgery. 47 patients

252 completed the study (Figure 1).

253 At baseline the patients had a median age of 55 years [range 24-73 years], and more than half of

254 the patients (56\%) were women. The mean disease duration was 5 years (SD 7.5), [range $<1-40$

255 years]. Sociodemographic and clinical baseline characteristics are shown in Table 1.

256 The mean fatigue measurements and their changes are shown in Table 2. At baseline we

257 observed significantly more severe fatigue in female than in male patients. The severity of

258 fatigue decreased significantly for both women and men between baseline and visit T1 and then

259 stabilized. This improvement was stronger for women $($ mean $(\mathrm{CI})=1.3(0.7,1.9), \mathrm{p}<0.001)$ than

260 for men, mean $(\mathrm{CI})=0.6(0.8,1.2), \mathrm{p}=0.026)$.

261 As shown in Table 3 the disease activity measured by DAS28 decreased significantly between

262 baseline and 3 months (mean $(\mathrm{CI})=1.4(1.1,1.7), \mathrm{p}<0.001)$ and was stable in later visits. The

263 same development was observed for the selected RAID subscales. In the linear mixed effects

264 model, sex and RAID emotional well-being contributed significantly to the model (Step 2 in

265 Table 4), while change in fatigue was not explained by disease activity (Step 1 in Table 4).

266 Analysis of predictors (Table 4) showed a higher reduction in fatigue values at follow-up visit T2

267 (6 months) for women than men $(\mathrm{p}=0.019)$. At follow-up visit T3 (12 months) there was a

268 significant change in fatigue for females $(\mathrm{p}=0.015)$. The changes in fatigue and the RAID

269 variables pain and physical and emotional wellbeing are explained by the gender component.

270 The change in fatigue is explained by both female sex and physical wellbeing, but in the end

271 female sex had stronger influence than physical wellbeing and turned out to be a significant

272 predictor for change in fatigue $(\mathrm{p}=0.010)$. 


\section{Discussion}

\section{Changes in patient-reported fatigue}

276 This study found that both female and male RA patients commencing biologic therapy reported

277 lower levels of fatigue during treatment. Previous research has shown somewhat inconsistent

278 results and, to our knowledge, has not examined gender differences. In a randomized clinical

279 trial, Norheim et al. (2012) reported no significant effect of biologics on fatigue in Sjögren's

280 patients. However, a post hoc analysis showed that six out of 12 patients in the group treated

281 with biologics reported a 50\% reduction in fatigue compared to one out of 13 in the placebo

282 group, and this result was significant. Another study investigated the effect of biologics on work

283 ability, functional disability and fatigue. The results from this observational study showed

284 significant improvements in fatigue after six months of biologic therapy (Hussain et al., 2015).

285 These inconsistencies may be explained by the fact that fatigue is a patient-reported symptom

286 with individual variations in severity and etiology and by the different diseases studied. In some

287 patients, fatigue may persist despite biologic therapy (Emery, 2014) and the explanation for this

288 may be found in the etiology of fatigue as a symptom with multiple causes, some connected to

289 disease activity and others to personal factors (Hewlett et al., 2011a). When RA patients with

290 fatigue were interviewed and encouraged to describe this problem in their own words, they

291 described fatigue as an experience that was always present, preventing them from finding

292 solutions to everyday problems and affecting both themselves and their social life (Bala et al.,

293 2016). A broader approach covering all aspects of this health problem is needed.

295 Possible predictors for changes in fatigue 
296 In bivariate analyses, disease activity and age turned out to be insignificant predictors for change

297 in fatigue at all follow-up visits. Pain also turned out to be an insignificant predictor for change

298 in fatigue in both bivariate and multivariate analyses. Emotional wellbeing turned out to be a

299 significant predictor for change in fatigue at the 6-month follow-up visit in bivariate analyses and

300 at the 12-month follow-up visit in multivariate analyses. In bivariate analyses physical well-

301 being was a statistically significant predictor of change in fatigue, but in multivariate analyses

302 only the 3-month follow-up visit showed a significant change in fatigue. Female sex was a

303 significant predictor in both bivariate and multivariate analyses. As far as we know, in previous

304 research sex has rarely been a variable in analyses of predictors of change in fatigue, and the

305 results of this study may be difficult to compare to other studies. However, it might be possible

306 to compare the results of the patient and health personnel-reported outcomes in this study. In a

307 systematic review, Madsen et al. (2016) found that disease activity was positively related to

308 fatigue when pain was not considered, and that pain was the dominating factor related to fatigue.

309 However, in these studies disease activity was measured using different components of DAS28,

310 and the various components of DAS28 have different weightings, with some of them being more

311 related to inflammation than others. It might therefore be difficult to compare the results of these

312 studies (Madsen et al., 2016).

313 In this study, women reported statistically significantly higher fatigue at baseline than men.

314 During the study the mean fatigue score was higher in women at all follow-up visits. Previous

315 work has shown that women report higher values of fatigue than men (Rat et al., 2012; Thyberg

316 et al., 2009), and several factors, such as genetic and hormonal factors and other exposures that

317 may be experienced differently by women and men, have been suggested as explanations for the

318 difference between men and women in terms of RA disease impact (van Vollenhoven, 2009). 
319 Pain and related measurements are often discussed as being non-sex-neutral. In a review, somatic

320 symptom reporting in women and men has been examined. Results showed that women reported

321 more numerous, more intense and more frequent bodily symptoms than men (Barsky, Peekna, \&

322 Borus, 2001). Moreover, women and men may react differently to treatment. In a register-based

323 observational study of predictors of response to biologic therapy, there was a lower remission

324 rate among female RA patients (Hyrich et al., 2006).

325 In this present study, multivariate analyses showed that change in fatigue is explained by both 326 female sex and physical wellbeing. Still, in the final model only female sex turned out to be a 327 significant predictor for change in fatigue.

\section{Strengths and limitations of the study}

330 The strength and importance of this study of fatigue in patients with rheumatoid arthritis is the

331 insight and information gained on patient-reported outcomes. The data are based on the

332 implementation of outcome measures recommended by experts (Hewlett, Dures, \& Almeida,

333 2011b), and guidelines from the European League Against Rheumatism and the American

334 College of Rheumatology (Aletaha et al., 2008), and recommendations from the international

335 research cooperation Outcome Measures in Rheumatoid Arthritis Clinical Trials (OMERACT)

336 (de Wit et al., 2013).

337 This study is a cohort study, without a control group. Therefore, it is difficult to determine

338 whether biologic therapy affects fatigue or not. On the other hand, the patients in the study had

339 tried standard treatment with synthetic DMARDs before commencing biologics. The patients'

340 level of fatigue was followed up for twelve months, and data collection was performed four

341 times, and this may provide valuable insight into how fatigue occurs. Furthermore, the number of 
342 participants was small, which means that the analyses have low statistical power, and they were

343 all recruited from the same rheumatology department. However, the participants were recruited

344 consecutively and were all in need of their first biologic treatment, and had no major co-

345 morbidities. The patients in the study live along the west coast of Norway, but we assume the

346 selection is not very different from the majority of RA patients living in other parts of Norway

347 (Brinkmann et al., 2018, Olsen et al., 2016).

348 Conclusion

349 Female RA patients commencing biologics report reductions in fatigue after 3 and 6 months.

350 After 12 months there is a slight increase in the fatigue level. Male RA patients report reductions

351 in fatigue after 3 and 12 months. When comparing sociodemographic, patient-reported and

352 health personnel-reported variables, female sex was a significant predictor of changes in fatigue.

353 This result is important and may indicate gender differences in the impact of RA. Further

354 research is needed in order to understand the complexity of fatigue and to evaluate non-

355 pharmacological treatment.

356

357 Relevance to clinical practice

358 Fatigue is a burdensome symptom in RA patients, and despite improvements in the

359 pharmacological treatment of RA, patients still report fatigue (van Hoogmoed et al., 2013; Druce

360 et al., 2015b; Madsen et al., 2016). Therefore, additional therapies are needed to combat fatigue.

361 These therapies should take into account that fatigue is a multifaceted health problem

362 encompassing personal and emotional factors in addition to the clinical factors directly

363 connected to the disease. 


\section{References}

366

367

368

369

370

371

372

373

374

375

376

377

378

379

380

381

382

383

384

385

386

387

388

389

390

391

392

393

394

395

396

397

398

399

400

401

402

403

404

405

406

407

408

409
Ahmed, S., Berzon, R. A., Revicki, D. A., Lenderking, W. R., Moinpour, C. M., Basch, E., . . . Wu, A. W. (2012). The use of patient-reported outcomes (PRO) within comparative effectiveness research: implications for clinical practice and health care policy. Med Care, 50(12), 1060-1070. doi: 10.1097/MLR.0b013e318268aaff

Aletaha, D., Landewe, R., Karonitsch, T., Bathon, J., Boers, M., Bombardier, C., . . Felson, D. (2008). Reporting disease activity in clinical trials of patients with rheumatoid arthritis: EULAR/ACR collaborative recommendations. Arthritis Rheum, 59(10), 1371-1377. doi: $10.1002 /$ art. 24123

Aletaha, D., Neogi, T., Silman, A. J., Funovits, J., Felson, D. T., Bingham, C. O., 3rd, ... Hawker, G. (2010). 2010 Rheumatoid arthritis classification criteria: an American College of Rheumatology/European League Against Rheumatism collaborative initiative. Arthritis Rheum, 62(9), 2569-2581. doi: 10.1002/art.27584

Almeida, C., Choy, E. H. S., Hewlett, S., Kirwan, J. R., Cramp, F., Chalder, T., Pollock, J., \& Christensen, R. (2016). Biologic interventions for fatigue in rheumatoid arthritis. Cochrane Database of Systematic Reviews 6. Art. No.: CD008334. doi: 10.1002/14651858.CD008334.pub2.

Asprusten, T. T., Sulheim, D., Fagermoen, E., Winger, A., Skovlund, E., \& Wyller, V. B. (2018). Systemic exertion intolerance disease diagnostic criteria applied on an adolescent chronic fatigue syndrome cohort: evaluation of subgroup differences and prognostic utility. $B M J$ Paediatrics Open, 2(1), e000233.

Bala, S. V., Samuelson, K., Hagell, P., Fridlund, B., Forslind, K., Svensson, B., \& Thome, B. (2016). Living with persistent rheumatoid arthritis: a BARFOT study. J Clin Nurs. doi: 10.1111/jocn. 13691

Barsky, A. J., Peekna, H. M., \& Borus, J. F. (2001). Somatic Symptom Reporting in Women and Men. J Gen Intern Med, 16(4), 266-275. doi: 10.1046/j.1525-1497.2001.00229.x

Brinkmann, G. H., Norvang, V., Norli, E. S., Grøvle, L., Haugen, A. J., Lexberg, Å. S., ... Lie, E. (2018). Treat to target strategy in early rheumatoid arthritis versus routine care - A comparative clinical practice study. Semin Arthritis Rheum. pii: S0049-0172(18)30184-7. doi: 10.1016/j.semarthrit.2018.07.004

Buyuktas, D., Hatemi, G., Yuksel-Findikoglu, S., Ugurlu, S., Yazici, H., \& Yurdakul, S. (2015). Fatigue is correlated with disease activity but not with the type of organ involvement in Behcet's syndrome: a comparative clinical survey. Clin Exp Rheumatol, 33(6 Suppl 94), S107-112.

De Rodez Benavent, S. A., Nygaard, G. O., Harbo, H. F., Tønnesen, S., Sowa, P., Landrø, N. I., ... Laeng, B. (2017). Fatigue and cognition: Pupillary responses to problem-solving in early multiple sclerosis patients. Brain and Behavior, 7(7), e00717

de Wit, M., Abma, T., Koelewijn-van Loon, M., Collins, S., \& Kirwan, J. (2013). Involving patient research partners has a significant impact on outcomes research: a responsive evaluation of the international OMERACT conferences. BMJ Open, 3(5). doi: 10.1136/bmjopen-2012-002241

Diniz, L. R., Balsamo, S., Souza, T. Y., Muniz, L. F., Martins, W. R., \& Mota, L. M. H. D. (2017). Measuring fatigue with multiple instruments in a Brazilian cohort of early rheumatoid arthritis patients. Rev Bras Reumatol (Engl Ed.), 57(5):431-437. doi: $10.1016 /$ j.rbre.2017.05.004 
410 Druce, K. L., Jones, G. T., Macfarlane, G. J., \& Basu, N. (2015b). Patients receiving anti-TNF

411

412

413

414

415

416

417

418

419

420

421

422

423

424

425

426

427

428

429

430

431

432

433

434

435

436

437

438

439

440

441

442

443

444

445

446

447

448

449

450

451

452

453

454

455 therapies experience clinically important improvements in RA-related fatigue: results from the British Society for Rheumatology Biologics Register for Rheumatoid Arthritis. Rheumatology (Oxford), 54(6), 964-971. doi: 10.1093/rheumatology/keu390

Druce, K. L., Jones, G. T., Macfarlane, G. J., Verstappen, S. M., \& Basu, N. (2015a). The Longitudinal Course of Fatigue in Rheumatoid Arthritis: Results from the Norfolk Arthritis Register. J Rheumatol, 42(11), 2059-2065. doi: 10.3899/jrheum.141498

Dupond, J. L. (2010). Fatigue in patients with rheumatic diseases. Joint Bone Spine, 78(2):15660. doi: 10.1016/j.jbspin.2010.05.002

Emery, P. (2014). Why is there persistent disease despite biologic therapy? Importance of early intervention. Arthritis Res Ther, 16(3), 115. doi: 10.1186/ar4594

Feldthusen, C., Bjork, M., Forsblad-d'Elia, H., \& Mannerkorpi, K. (2013). Perception, consequences, communication, and strategies for handling fatigue in persons with rheumatoid arthritis of working age--a focus group study. Clin Rheumatol, 32(5), 557566. doi: 10.1007/s10067-012-2133-y

Fransen, J., Creemers, M. C., \& van Riel, P. L. (2004). Remission in rheumatoid arthritis: agreement of the disease activity score (DAS28) with the ARA preliminary remission criteria. Rheumatology (Oxford), 43(10), 1252-1255. doi: 10.1093/rheumatology/keh297

Fransen, J., Stucki, G., \& van Riel, P. L. C. M. (2003). Rheumatoid Arthritis Measures: Disease Activity Score (DAS), Disease Activity Score-28 (DAS28), Rapid Assessment of Disease Activity in Rheumatology (RADAR), and Rheumatoid Arthritis Disease Activity Index (RADAI). Arthritis Care \& Research, 49(5S), S214-S224 doi: 10.1002/art.11407

Gok Metin, Z., \& Ozdemir, L. (2016). The Effects of Aromatherapy Massage and Reflexology on Pain and Fatigue in Patients with Rheumatoid Arthritis: A Randomized Controlled Trial. Pain Manag Nurs. 17(2):140-9. doi: 10.1016/j.pmn.2016.01.004

Gossec, L., Dougados, M., \& Dixon, W. (2015). Patient-reported outcomes as end points in clinical trials in rheumatoid arthritis. RMD Open, 1(1), e000019. doi: 10.1136/rmdopen2014-000019

Gossec, L., Dougados, M., Rincheval, N., Balanescu, A., Boumpas, D. T., Canadelo, S., . . Kvien, T. K. (2009). Elaboration of the preliminary Rheumatoid Arthritis Impact of Disease (RAID) score: a EULAR initiative. Ann Rheum Dis, 68(11), 1680-1685. doi: 10.1136/ard.2008.100271

Heiberg, T., Austad, C., Kvien, T. K., \& Uhlig, T. (2011). Performance of the Rheumatoid Arthritis Impact of Disease (RAID) score in relation to other patient-reported outcomes in a register of patients with rheumatoid arthritis. Ann Rheum Dis, 70(6), 1080-1082. doi: 10.1136/ard.2010.143032

Hewlett, S., Chalder, T., Choy, E., Cramp, F., Davis, B., Dures, E., . . Kirwan, J. (2011a). Fatigue in rheumatoid arthritis: time for a conceptual model. Rheumatology (Oxford), 50(6), 1004-1006. doi: 10.1093/rheumatology/keq282

Hewlett, S., Cockshott, Z., Byron, M., Kitchen, K., Tipler, S., Pope, D., \& Hehir, M. (2005). Patients' perceptions of fatigue in rheumatoid arthritis: overwhelming, uncontrollable, ignored. Arthritis Rheum, 53(5), 697-702. doi: 10.1002/art.21450

Hewlett, S., Dures, E., \& Almeida, C. (2011b). Measures of fatigue: Bristol Rheumatoid Arthritis Fatigue Multi-Dimensional Questionnaire (BRAF MDQ), Bristol Rheumatoid Arthritis Fatigue Numerical Rating Scales (BRAF NRS) for severity, effect, and coping, Chalder Fatigue Questionnaire (CFQ), Checklist Individual Strength (CIS20R and CIS8R), 
456

457

458

459

460

461

462

463

464

465

466

467

468

469

470

471

472

473

474

475

476

477

478

479

480

481

482

483

484

485

486

487

488

489

490

491

492

493

494

495

496

497

498

499

500

Fatigue Severity Scale (FSS), Functional Assessment Chronic Illness Therapy (Fatigue) (FACIT-F), Multi-Dimensional Assessment of Fatigue (MAF), Multi-Dimensional Fatigue Inventory (MFI), Pediatric Quality Of Life (PedsQL) Multi-Dimensional Fatigue Scale, Profile of Fatigue (ProF), Short Form 36 Vitality Subscale (SF-36 VT), and Visual Analog Scales (VAS). Arthritis Care Res (Hoboken), 63 Suppl 11, S263-286. doi: 10.1002/acr.20579

Hussain, W., Janoudi, N., Noorwali, A., Omran, N., Baamer, M., Assiry el, H., . . Almoallim, H. (2015). Effect of Adalimumab on Work Ability Assessed in Rheumatoid Arthritis Disease Patients in Saudi Arabia (AWARDS). Open Rheumatol J, 9, 46-50. doi: 10.2174/1874312901409010046

Hyrich, K. L., Watson, K. D., Silman, A. J., \& Symmons, D. P. (2006). Predictors of response to anti-TNF-alpha therapy among patients with rheumatoid arthritis: results from the British Society for Rheumatology Biologics Register. Rheumatology (Oxford), 45(12), 15581565. doi: 10.1093/rheumatology/kel149

Johansen, H., Bathen, T., Andersen, L. Ø., Rand-Hendriksen, S., \& Østlie, K. (2018). Chronic pain and fatigue in adults with congenital unilateral upper limb deficiency in Norway. A cross-sectional study. PLoS ONE, 13(1), e0190567.

Kirwan, J. R., Minnock, P., Adebajo, A., Bresnihan, B., Choy, E., de Wit, M., . . Hewlett, S. (2007). Patient perspective: fatigue as a recommended patient centered outcome measure in rheumatoid arthritis. J Rheumatol, 34(5), 1174-1177.

Krupp, L. B., LaRocca, N. G., Muir-Nash, J., \& Steinberg, A. D. (1989). The fatigue severity scale. Application to patients with multiple sclerosis and systemic lupus erythematosus. Arch Neurol, 46(10), 1121-1123.

Lami, M. J., Martinez, M. P., Sanchez, A. I., Miro, E., Diener, F. N., Prados, G., \& Guzman, M. A. (2016). Gender Differences in Patients with Fibromyalgia Undergoing CognitiveBehavioral Therapy for Insomnia: Preliminary Data. Pain Pract, 16(2), E23-34. doi: 10.1111/papr.12411

Lindstrom Egholm, C., Krogh, N. S., Pincus, T., Dreyer, L., Ellingsen, T., Glintborg, B., .. . Hetland, M. L. (2015). Discordance of Global Assessments by Patient and Physician Is Higher in Female than in Male Patients Regardless of the Physician's Sex: Data on Patients with Rheumatoid Arthritis, Axial Spondyloarthritis, and Psoriatic Arthritis from the DANBIO Registry. J Rheumatol, 42(10), 1781-1785. doi: 10.3899/jrheum.150007

Madsen, S. G., Danneskiold-Samsoe, B., Stockmarr, A., \& Bartels, E. M. (2016). Correlations between fatigue and disease duration, disease activity, and pain in patients with rheumatoid arthritis: a systematic review. Scand J Rheumatol, 45(4), 255-261. doi: 10.3109/03009742.2015.1095943

Matcham, F., Ali, S., Hotopf, M., \& Chalder, T. (2015). Psychological correlates of fatigue in rheumatoid arthritis: a systematic review. Clin Psychol Rev, 39, 16-29. doi: 10.1016/j.cpr.2015.03.004

Nikolaus, S., Bode, C., Taal, E., \& van de Laar, M. A. (2013). Fatigue and factors related to fatigue in rheumatoid arthritis: a systematic review. Arthritis Care Res (Hoboken), 65(7), 1128-1146. doi: 10.1002/acr.21949

Norheim, K. B., Harboe, E., Goransson, L. G., \& Omdal, R. (2012). Interleukin-1 inhibition and fatigue in primary Sjogren's syndrome--a double blind, randomised clinical trial. PLoS One, 7(1), e30123. doi: 10.1371/journal.pone.0030123 
501 Olsen, C. L., Lie, E., Kvien, T. K., \& Zangi, H. A. (2016). Predictors of Fatigue in Rheumatoid

502

503

504

505

506

507

508

509

510

511

512

513

514

515

516

517

518

519

520

521

522

523

524

525

526

527

528

529

530

531

532

533

534

535

536

537

538

539

540

541 Arthritis Patients in Remission or in a Low Disease Activity State. Arthritis Care \& Research 68(7), 1043-1048. doi: 10.1002/acr.22787

Pinheiro, J., Bates, D., DebRoy, S., Sarkar, D., \& R Core Team. (2016). Linear and Nonlinear Mixed Effects Models (Version 3.1-127). Retrieved from http://CRAN.Rproject.org/package $=$ nlme $>$

Pouchot, J., Kherani, R. B., Brant, R., Lacaille, D., Lehman, A. J., Ensworth, S., . . Liang, M. H. (2008). Determination of the minimal clinically important difference for seven fatigue measures in rheumatoid arthritis. J Clin Epidemiol, 61(7), 705-713. doi: 10.1016/j.jclinepi.2007.08.016

R Core team. (2016). R: A language and environment for statistical computing. Vienna, Austria: R Foundation for Statistical Computing. Retrieved from https:/www.R- project.org/

Rat, A. C., Pouchot, J., Fautrel, B., Boumier, P., Goupille, P., \& Guillemin, F. (2012). Factors associated with fatigue in early arthritis: results from a multicenter national French cohort study. Arthritis Care Res (Hoboken), 64(7), 1061-1069. doi: 10.1002/acr.21647

Scott, D. L., Wolfe, F., \& Huizinga, T. W. (2010). Rheumatoid arthritis. Lancet, 376(9746), 1094-1108. doi: 10.1016/s0140-6736(10)60826-4

Studenic, P., Radner, H., Smolen, J. S., \& Aletaha, D. (2012). Discrepancies between patients and physicians in their perceptions of rheumatoid arthritis disease activity. Arthritis Rheum, 64(9), 2814-2823. doi: 10.1002/art.34543

Thyberg, I., Dahlstrom, O., \& Thyberg, M. (2009). Factors related to fatigue in women and men with early rheumatoid arthritis: the Swedish TIRA study. J Rehabil Med, 41(11), 904912. doi: 10.2340/16501977-0444

Valko, P. O., Bassetti, C. L., Bloch, K. E., Held, U., \& Baumann, C. R. (2008). Validation of the fatigue severity scale in a Swiss cohort. Sleep, 31(11), 1601-1607.

van Hoogmoed, D., Fransen, J., Repping-Wuts, H., Spee, L., Bleijenberg, G., \& van Riel, P. L. (2013). The effect of anti-TNF-alpha vs. DMARDs on fatigue in rheumatoid arthritis patients. Scand J Rheumatol, 42(1), 15-19. doi: 10.3109/03009742.2012.709878

van Riel, P. L. (2014). The development of the disease activity score (DAS) and the disease activity score using 28 joint counts (DAS28). Clin Exp Rheumatol, 32(5 Suppl 85), S-6574.

van Tuyl, L. H., Sadlonova, M., Hewlett, S., Davis, B., Flurey, C., Goel, N., . . Boers, M. (2016). The patient perspective on absence of disease activity in rheumatoid arthritis: a survey to identify key domains of patient-perceived remission. Ann Rheum Dis. doi: 10.1136/annrheumdis-2016-209835

van Vollenhoven, R. F. (2009). Sex differences in rheumatoid arthritis: more than meets the eye. BMC Med, 7, 12. doi: 10.1186/1741-7015-7-12

Whitehead, L. (2009). The measurement of fatigue in chronic illness: a systematic review of unidimensional and multidimensional fatigue measures. J Pain Symptom Manage, 37(1), 107-128. doi: 10.1016/j.jpainsymman.2007.08.019

PeerJ reviewing PDF | (2018:05:28575:2:0:NEW 18 Feb 2019) 
Figure 1

Flowchart

Flowchart to show number of participants who completed the study.

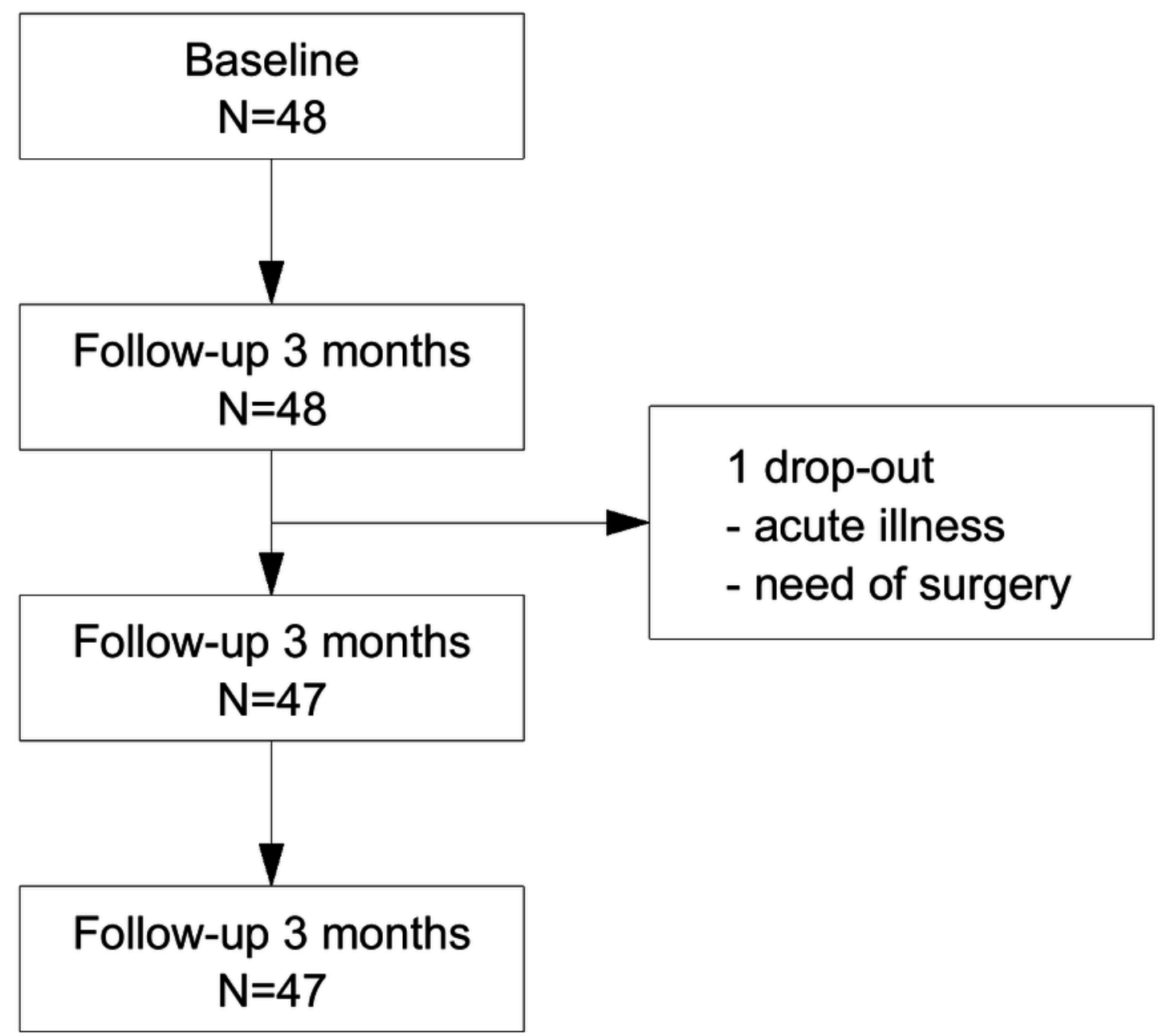




\section{Table $\mathbf{1}$ (on next page)}

\section{Sociodemographic and clinical characteristics}

Sociodemographic characteristics such as age, sex, civil status, children living at home, occupational activity.

Clinical characteristics such as disease duration, rheumatoid factor, anti-cyclic citrullinated peptide, erythrocyte sedimentation rate, C-reactive protein, Disease Activity Score of 28 joints, Fatigue Severity Scale, Rheumatoid Arthritis Impact of Disease. 
Table 1 Sociodemographic and clinical characteristics

Sociodemographic characteristics

Age, years, median (range)

Sex, female, $n$ (\%)

Married/living with partner, $\mathrm{n}(\%)$

Children living at home, $\mathrm{n}(\%)$

Working or studying (full-time or part-time), n (\%)

Working or studying patients on sick leave, $n(\%)$

Disability benefits (full-time or part-time), $\mathrm{n}(\%)$

Retired, $\mathrm{n}(\%)$

\section{Clinical characteristics}

Disease duration, years, mean (SD)

$\mathrm{RF}, \mathrm{n}(\%)$

Anti-CCP, n (\%)

$\operatorname{ESR}(\mathrm{mm} / \mathrm{h})$, median (range)

$\mathrm{CRP}(\mathrm{mg} / \mathrm{L})$, median (range)

Prednisolon dosage, mean (SD) ${ }^{\mathrm{a}}$

Methotrexate dosage, mean (SD) ${ }^{\mathrm{b}}$

FSS, (1-7), mean (SD) ${ }^{c}$

DAS28, mean (SD)

RAID - pain, mean (SD) ${ }^{\mathrm{d}}$

RAID - emotional well-being, mean (SD) ${ }^{e}$

RAID - physical well-being, mean (SD) ${ }^{\mathrm{d}}$ $n=48$

$55.0[24-73]$

$27(56 \%)$

$34(71 \%)$

$22(46 \%)$

$24(50 \%)$

$10(21 \%)$

$10(21 \%)$

$4(8 \%)$

$5.0(7.5)$

$33(69 \%)$

$38(79 \%)$

$22.5[0-75]$

$9.0[0-58]$

$6.0(3.2)$

$20.0(4.8)$

$4.4(1.5)$

$4.5(1.2)$

$5.5(2.1)$

$3.9(2.1)$

$4.9(1.9)$

2 RF, rheumatoid factor; Anti-CCP, anti-cyclic citrullinated peptide; ESR, erythrocyte

3 sedimentation rate; CRP, C-reactive protein; DAS28, Disease Activity Score of 28 joints; FSS,

4 Fatigue Severity Scale; RAID, Rheumatoid Arthritis Impact of Disease

$5{ }^{a} n=28,{ }^{b} n=38,{ }^{c} n=47,{ }^{d} n=45,{ }^{e} n=44$

6 
Table 2 (on next page)

Changes in fatigue, and gender differences

Changes in fatigue, and gender differences 
Table 2 Mean, 95\% confidence intervals and p-values of changes in fatigue during the study, and test of differences between women and men

\begin{tabular}{|c|c|c|c|c|c|c|c|c|c|c|}
\hline \multirow[b]{3}{*}{ Time point } & \multirow[b]{3}{*}{ Missing } & \multicolumn{4}{|c|}{ Women } & \multicolumn{4}{|c|}{ Men } & \multirow{3}{*}{$\begin{array}{l}\text { FSS difference } \\
\text { Men/women } \\
\text { p }\end{array}$} \\
\hline & & \multicolumn{2}{|c|}{$\overline{F S S}$} & \multicolumn{2}{|c|}{ FSS change from T0 } & \multicolumn{2}{|c|}{ FSS } & \multicolumn{2}{|c|}{ FSS change from T0 } & \\
\hline & & $\mathrm{n}$ & Mean $(95 \% \mathrm{CI})$ & Mean $(95 \% \mathrm{CI})$ & $\mathrm{p}$ & $\bar{n}$ & Mean $(95 \% \mathrm{CI})$ & Mean (95\% CI) & $\mathrm{p}$ & \\
\hline Baseline (T0) & 1 & $\begin{array}{l}2 \\
6\end{array}$ & $5.0(4.5,5.5)$ & - & - & $\begin{array}{l}2 \\
1\end{array}$ & $3.6(2.9,4.3)$ & - & - & $0.001 *$ \\
\hline 3 months (T1) & 0 & $\begin{array}{l}2 \\
7\end{array}$ & $3.7(3.1,4.4)$ & $1.3(0.7,1.9)$ & $<0.001 \uparrow$ & $\begin{array}{l}2 \\
1\end{array}$ & $3.0(2.3,3.6)$ & $0.6(0.8,1.2)$ & $\begin{array}{l}0,026 \\
\dagger\end{array}$ & $0.113^{*}$ \\
\hline 6 months (T2) & 0 & $\begin{array}{l}2 \\
7\end{array}$ & $3.4(2.7,4.1)$ & $1.6(0.9,2.3)$ & $<0.001 \dagger$ & $\begin{array}{l}2 \\
0\end{array}$ & $3.0(2.3,3.7)$ & $0.6(-0.3,1.5)$ & $\begin{array}{l}0,155 \\
\dagger\end{array}$ & $0.368^{*}$ \\
\hline 12 months (T3) & 2 & $\begin{array}{l}2 \\
5\end{array}$ & $3.7(2.9,4.4)$ & $1.4(0.7,2.0)$ & $<0.001 \dagger$ & $\begin{array}{l}2 \\
0\end{array}$ & $2.7(1.9,3.5)$ & $0.9(0.1,1.6)$ & $\begin{array}{l}0,024 \\
\dagger\end{array}$ & $0.078^{*}$ \\
\hline
\end{tabular}

FSS, Fatigue severity scale, scale $0-7$ : lower scores represent less fatigue

Confidence interval, $\mathrm{CI}$

$\dagger$ paired $t$-test

$* t$-test 


\section{Table 3(on next page)}

Disease activity, pain, physical and emotional well-being during the one-year observation study of fatigue, including both women and men

Disease activity, pain, physical and emotional well-being during the one-year observation study of fatigue, including both women and men 
Table 3 Mean changes, 95\% confidence intervals and $p$-values during the one-year observation study of fatigue, including both women and men

\begin{tabular}{|c|c|c|c|c|c|c|}
\hline Measure & $T 1$ : change from $T 0$ & & $T 2$ : change from $T 0$ & & 3: change from $T 0$ & \\
\hline & Mean $(95 \% \mathrm{CI})$ & $p$ & Mean $(95 \% \mathrm{CI})$ & $p$ & Mean (95 CI) & $p$ \\
\hline DAS28 & $1.4(1.1,1.7)$ & $<0.001 \dagger$ & $1.4(1.1,1.8)$ & $<0.001 \dagger$ & $1.6(1.3,1.9)$ & $<0.001 \uparrow$ \\
\hline RAID pain ${ }^{1}$ & $2.4(1.6,3.3)$ & $<0.001 \uparrow$ & $2.2(2.8,0.4)$ & $<0.001 \uparrow$ & $3.2(2.3,4.0)$ & $<0.001 \uparrow$ \\
\hline RAID emotional well-being ${ }^{2}$ & $1.4(0.7,2.1)$ & $<0.001 \dagger$ & $1.7(1.0,2.4)$ & $<0.001 \dagger$ & $1.3(0.3,2.2)$ & $0.012 \dagger$ \\
\hline
\end{tabular}

6

T0: before the intervention; $T 1$ : after three months; $T 2$ : after six months; $T 3$ : after twelve months

${ }^{1}$ Scale 0-10: lower scores represent less pain

${ }^{2}$ Scale 0-10: lower scores represent more well-being

DAS28, Disease activity score 28

RAID, Rheumatoid Arthritis Impact of Disease

Confidence interval, CI

$\dagger$ paired $t$-test 


\section{Table 4 (on next page)}

Predictors of fatigue: Mean changes, $95 \%$ confidence intervals and $p$-values, including both women and men

Predictors of fatigue. Model 1 with one predictor (main effect and interaction). Model 2 including sex, RAID physical well-being, RAID emotional well-being and RAID pain. Model 3 including sex and RAID physical well-being. Mean changes, 95\% confidence intervals and $p$ values, including both women and men 
Table 4 Predictors of fatigue: Mean changes, 95\% confidence intervals and $p$-values, including both women and men

\begin{tabular}{|c|c|c|c|c|c|c|c|}
\hline \multirow[b]{2}{*}{ Predictor } & \multirow[b]{2}{*}{ Effect type } & \multicolumn{2}{|l|}{ Step $1^{1}$} & \multicolumn{2}{|l|}{ Step $2^{2}$} & \multicolumn{2}{|l|}{ Final model $^{3}$} \\
\hline & & B $(95 \% C I)$ & p-value & B (95\%CI) & p-value & B $(95 \% C I)$ & p-value \\
\hline \multirow[t]{4}{*}{ DAS28 } & Main effect & $0.06(-0.26,0.38)$ & ,706 & - & - & - & - \\
\hline & Effect change: BL -> 3 months & $0.34(-0.09,0.76)$ &, 126 & - & - & - & - \\
\hline & Effect change: $\mathrm{BL}->6$ months & $0.13(-0.32,0.59)$ &, 569 & - & - & - & - \\
\hline & Effect change: BL -> 12 months & $-0.02(-0.46,0.43)$ & ,937 & - & - & - & - \\
\hline \multirow[t]{4}{*}{ Age } & Main effect & $-0.04(-0.08,0)$ &, 081 & - & - & - & - \\
\hline & Effect change: $\mathrm{BL}->3$ months & $0(-0.04,0.04)$ &, 856 & - & - & - & - \\
\hline & Effect change: $\mathrm{BL}->6$ months & $0.03(-0.02,0.07)$ & ,234 & - & - & - & - \\
\hline & Effect change: $\mathrm{BL}->12$ months & $0.02(-0.03,0.06)$ &, 450 & - & - & - & - \\
\hline \multirow[t]{4}{*}{ Sex } & Main effect & $1.49(0.54,2.43)$ &, 003 & $1.27(0.34,2.2)$ & ,013 & $1.29(0.36,2.23)$ &, 010 \\
\hline & Effect change: $\mathrm{BL}->3$ months & $-0.56(-1.45,0.34)$ & ,235 & $0.09(-0.17,0.34)$ &, 524 & $0.12(-0.08,0.32)$ & ,255 \\
\hline & Effect change: $\mathrm{BL}->6$ months & $-1.13(-2.05,-0.21)$ &, 019 & $0.03(-0.16,0.22)$ &, 802 & $-0.57(-1.46,0.32)$ & ,220 \\
\hline & Effect change: BL -> 12 months & $-0.58(-1.52,0.36)$ & ,236 & $0.04(-0.16,0.25)$ & ,687 & $-1.19(-2.11,-0.27)$ & ,015 \\
\hline \multirow{4}{*}{$\begin{array}{l}\text { RAID } \\
\text { physical } \\
\text { well-being }\end{array}$} & Main effect & $0.2(0.01,0.39)$ &, 047 & $-0.69(-1.56,0.18)$ &, 144 & $-0.38(-1.31,0.55)$ & ,440 \\
\hline & Effect change: $\mathrm{BL}->3$ months & $0.13(-0.13,0.38)$ & ,336 & $-1.15(-2.03,-0.28)$ &, 016 & $0.19(-0.06,0.45)$ & , 155 \\
\hline & Effect change: $\mathrm{BL}->6$ months & $0.04(-0.21,0.28)$ & ,773 & $-0.38(-1.27,0.5)$ & ,423 & $0.14(-0.11,0.4)$ & ,284 \\
\hline & Effect change: $\mathrm{BL}->12$ months & $-0.06(-0.32,0.2)$ & ,649 & $0.15(-0.19,0.49)$ & ,418 & $0.02(-0.25,0.28)$ & ,912 \\
\hline \multirow{4}{*}{$\begin{array}{l}\text { RAID } \\
\text { emotional } \\
\text { well-being }\end{array}$} & Main effect & $0.14(-0.03,0.31)$ &, 113 & $-0.15(-0.54,0.23)$ & ,464 & - & - \\
\hline & Effect change: BL -> 3 months & $0.16(-0.08,0.39)$ & ,199 & $-0.12(-0.52,0.27)$ &, 561 & - & - \\
\hline & Effect change: $\mathrm{BL}->6$ months & $0.31(0.07,0.56)$ &, 016 & $0.09(-0.21,0.39)$ &, 591 & - & - \\
\hline & Effect change: BL -> 12 months & $0.02(-0.2,0.23)$ &, 882 & $0.39(0.09,0.68)$ &, 015 & - & - \\
\hline \multirow{4}{*}{$\begin{array}{l}\text { RAID } \\
\text { pain }\end{array}$} & Main effect & $0.1(-0.08,0.29)$ & ,283 & $0.04(-0.26,0.35)$ & ,782 & - & - \\
\hline & Effect change: $\mathrm{BL}->3$ months & $0.08(-0.17,0.32)$ &, 540 & $0.01(-0.25,0.28)$ & ,919 & - & - \\
\hline & Effect change: BL -> 6 months & $0.14(-0.1,0.38)$ & ,257 & $0.11(-0.23,0.45)$ &, 541 & - & - \\
\hline & Effect change: BL -> 12 months & $0.08(-0.19,0.35)$ &, 552 & $0.14(-0.18,0.46)$ & ,422 & - & - \\
\hline
\end{tabular}

${ }^{1}$ Model with one predictor (main effect and interaction). ${ }^{2}$ Model including sex, RAID physical well-being, RAID emotional well-being, RAID pain. ${ }^{3}$ Model including sex, RAID physical well-being

BL, baseline; CI, confidence interval; DAS28, Disease Activity Score of 28 joints; RAID, Rheumatoid Arthritis Impact of Disease 